types. Dr. Lonsdale's observed effects are in fact very similar to the kind of abnormality observed in the X-ray spectra of age-hardened alloys and alloys with high magnetic coercivity; they suggest a laminated structure.

There has recently appeared in India a "Symposium of Papers on the Structure and Properties of Diamond" inspired by an idea due to Sir C. V. Raman ${ }^{3}$. The symposium runs to more than 150 pages and contains seventeen papers by Raman and his colleagues. The fundamental idea, contributed by Raman, is that there are four structurally possible arrangements of carbon atoms which are all in agreement with $\mathrm{X}$-ray data. Two of these, which, following Raman, we may label $T d$ I and $T d$ II, will give a crystal with tetrahedral symmetry; and two, Oh I and $O h$ II, will produce the full octahedral symmetry. The two tetrahedral types are physically identical but geometrically different: the octahedral types are physically distinct and might have slightly different lattice parameters.

Raman then supposes that something in the nature of twinning or parallel growth of these different but closely allied types occurs. Twinning of the two $T d$ types would be dificult to detect as it would produce little, if any, internal strain on the crystal. But union of a $T d$ with either of the $O h$ types might be detectable as a result of strains due to slightly different lattice spacings. Twins of the two $O h$ types might also produce observable strains. Raman thus suggests that there are more than the two types recognized by Robertson, Fox and Martin, and that some diamonds may be 'mixtures' of the different types. The position can perhaps be best summarized in tabular form; the lower part of the table is derived from material taken from the Indian symposium.

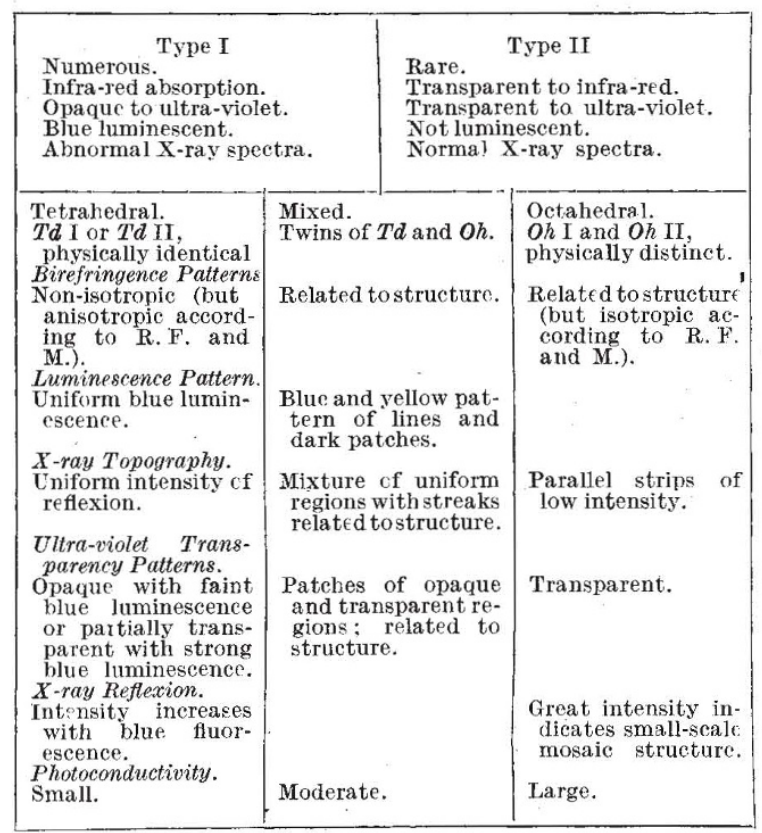

The evidence in support of Raman's theory is really supplied by those experiments which indicate that a particular diamond is not homogeneous. These are the experiments on birefringence (where the results are at variance with the observations of Robertson,
Fox and Martin), luminescence and ultra-violet transparency patterns. The item in the table "X-ray Topography" deserves some fuller explanation; under this title G. N. Ramachandran describes an ingenious method of obtaining an X-ray image of a crystal flake in which variations of reflecting power are recorded. Such variations appear to be related to the ultra-violet transparency and other properties of the diamonds.

The symposium is not wholly devoted to a demonstration that four different types of diamond do exist. There are several papers dealing with the properties without reference to the particular type. R. S. Krishnan contributes a paper on the Raman spectrum of diamond, based on Raman's interpretation of the dynamics of the crystal lattice, while B. Dayal applies the same ideas to the evaluation of the specific heat of diamond. An examination of the magnetic susceptibility by A. Sigamony shows that this property is not structure sensitive and that it does not ehange when a fluorescent diamond is irradiated with an intense beam of light.

The symposium concludes with an interesting paper by S. Ramaseshan describing the external form and surface markings of twenty-nine diamonds from Panna in their natural state. Considering the perfection usually ascribed to diamonds, the marked curvature of the faces of natural crystals is not without interest.

The authors who have contributed to the symposium have been fortunate in having at their disposal a collection of 310 diamonds made by Sir C. V. Raman. This wealth of material has been an undoubted help to them, and contributes effectively to the value of the work they have carried out. There is evidently an interesting problem here, not yet completely solved; one key to it lies in a more complete understanding of the abnormal X-ray reflexions recorded by Lonsdale and Smith.

G. D. Preston.

${ }^{1}$ Robertson, Fox and Martin, Phil. Trans. Roy. Soc., A, 1232, 463 (1934); Proc. Roy. Soc., A, 157, 579 (1936).

${ }^{2}$ Lonsdale and Smith, Nature, 148, 112 (1941).

${ }^{3}$ Raman and others, Proc. Indian Acad. Sci., Bangalore, 189--342 (1944).

\section{SOIL CONSERVATION IN THE ANGLO-EGYPTIAN SUDAN}

\author{
By E. N. CORBYN \\ Formerly Governor of Khartoum
}

N December 1942, a committee was appointed by the Governor-General of the Anglo-Egyptian Sudan to consider the problem of soil conservation in the Sudan; it was constituted as follows: Dr. J. D. Tothill, director of agriculture and forests; Lieut.-Colonel C. P. Fisher, director of the veterinary service; Mr. J. Smith, chief conservator of forests ; Mr. G. Andrew, Government geologist; and Messrs. G. M. Hancock and B. Kennedy-Cooke, Sudan Political Service. The Committee's report has just been issued*.

The terms of reference of the Committee were: (a) To report on the present situation in the Sudan with regard to soil erosion and desiccation and the

* The Report of the Soil Conservation Committee, Sudan Government, 1944. Pp: $161+12+2$ maps. (Khartoum: MeCorciuodale and Co. (Sudan), Ltd.; obtainable from Sudan Government London Office, Wellington House, Buckingham Gate, S.W.1.) 2s, 6d. net. 
availability of rural water supplies for the human and animal population. (b) To make recommendations in respect of any of the above matters and of any measures of legislation or taxation which may be required for the carrying out of such recommendations. (c) To draw up a programme of work covering a stated period of years for the implementation of the recommendations. $(d)$ To provide estimates of the capital cost of carrying out the programme and of the future maintenance costs involved.

The findings of the Committee are securely based on the best expert scientific knowledge available to the Government, and the standard of the Sudan in such matters is high. This powerful effort to lay down the broad lines on which, over a territory of a million square miles out of the eleven and a half millions which constitute Africa, the three-fold dangers of soil erosion, devegetation and desiccation shall be met, deserves the flattery of imitation by every governmental authority in that continent. How widespread is the desire of African Governments to deal with these menaces adequately was shown by the success of the International $\mathrm{Cc}^{-}$

in London to study them in 1942 by the Royal African Society, under the chairmanship of Prof. E. P. Stebbing, in which the cordial co-operation was obtained of the French and Belgian African administrations, and to which the Dutch Government contributed the fruits of its Asiatic experience.

The Sudan is particularly well placed to state whether there is a 'desert creep' of the Sahara southwards in its area, as it borders upon the south-eastern portion of the great Libyan Desert. The findings of the Committee are on the whole reassuring on this point; but this may be due in this region to something of a piece of geological good fortune, namely, the deposit, from the Sahara southwards to about lat. $10^{\circ} 30^{\prime} \mathrm{N}$., of a great 'blanket' of sand, dating from glacial times, which "has been static or fixed for several thousands of years . . . and is everywhere anchored or fixed by vegetation grading from light forest to heskanit [a tough grass] depending on local rainfall. . . . Being permeable in structure and fixed in position it prevents erosion from taking place". This sand forms, fortunately, a cultivable soil.

The clay plains south of this great area of 'continental' sand, and the clay plains of the major portion of the country in general, do not share the compara. tive immunity of the sand area from erosion, and their problem is similar to that of other parts of Africa.

The Committee does not consider that there has been any great alteration of climate in the direction of desiccation within historic times-say, the last 5,000 years. But it finds abundant evidence of alternations of both wet and dry periods in previous geological times. It concludes, therefore, that such desiccation and erosion as have taken place, and are taking place, are due to the activities of human beings and their animals, and can consequently be controlled by bringing about changes in these activities sufficient to restore damage and prevent further deterioration.

The Committee's survey of existing conditions in the Sudan showed many and serious examples of soil deterioration as at present taking place. Sheet erosion was found to be occurring in many places in the hill country of southern Kordofan and of Equatoria, and near the gullied land of the Blue Nile. Gully erosion was noted as common and locally important in Equatoria, along the banks of the Blue Nile, Dinder and Atbara Rivers, in the hills of Kordofan, and in the coastal range of Red Sea hills. Soil deterioration due to overgrazing, and overcropping was found to be common in all the thickly populated areas.

Deterioration of forest watersheds due to fires and grazing was observed as taking place in the Red Sea hills, in the hills of southern Kordofan and of the southern Fung and eastern Upper Nile districts, and in the hills and mountains of Equatoria, where it is sometimes also due to agricultural development of the heads of valleys.

Spoliation of agricultural land by silt dune formation was found to be taking place in the delta of the Khor (River) Baraka around Tokar. Spoliation of rain-watered agricultural land by out-of-season fires was noted as common on the clay plains of Kassala, Blue Nile, Upper Nile and Kordofan.

Finally, town and village peripheries were found to be deteriorating rapidly all over the country, owing to over-cultivation and over-grazing of the surrounding areas, and excessive cutting of trees for firewood in the neighbourhood of towns.

An extensive programme of more than fifty items, covering different danger-points spread over all the eight provinces of the Sudan, is put forward by the Committee, to some thirty of which a priority classification is given as matters of urgency.

The remedies recommended fall under main headings as follows :

(1) Methods of rain and flood-water control : gully plugging; contour terracing; protection of heads of catchment areas.

(2) Forest protection : reservation of forest areas to an increased extent; protection from fire; reafforestation; control of fire-wood supplies.

(3) Treatment of cultivable rain-watered grasslands: control of annual burning methods; fire protection.

(4) Control of town perimeters, including reservation of areas for the growing and supply of fodder for domestic animals, and for fire-wood, whether from near or distant sources; control of village planning, so far as necessary to ensure conservation and the best use of the soil of village areas; control of the grazing habits of nomads, so far as necessary to avoid deterioration in the soil of grazing areas.

Two great merits of the report are that its recommendations apply these remedies to definite schemes at definite places, and that financial estimates of the cost of these schemes on a basis of a five-year experimental period are worked out and provided, totalling in the first instance to a sum of $£ 300,000$, spread over five years, to be at the disposal of a board appointed for the purpose.

A considerable part of the Committee's recommendations falls under the heading of improvement of water supplies, a most important matter in so arid a country, and one which in itself will relieve the strain on soil surrounding the water-points which exist already in agricultural and grazing areas.

The Sudan Government has accepted the main recommendations of the Committee, and will make the necessary funds available for the five-year trial period envisaged. It has appointed a Water Supplies and Soil Conservation Board to administer the funds provided and to take executive action on the schemes proposed. 